\title{
AN ITERATIVE FORMULA FOR SIMULTANEOUS LOCATION OF THE ZEROS OF A POLYNOMIAL
}

\author{
Dr.Abdel Wahab Nourein \\ Dept. of Computer Science \\ Faculty of Computer Science and Information Technology \\ Karary University, Khartoum, Sudan
}

\begin{abstract}
Needless to say that the search for efficient algorithms for determining zeros of polynomials has been continually raised in many applications. In this paper we give a cubic iteration method for determining simultaneously all the zeros of a polynomial - assumed distinct - starting with 'reasonably close' initial approximations - also assumed distinct. The polynomial in question - is expressed in its Taylor series expansion in terms of the initial approximations and their correction terms. A formula with cubic rate of convergence - based on retaining terms up to $2^{\text {nd }}$ order of the expansion in the correction terms - is derived.
\end{abstract}

\section{INTRODUCTION}

The problem of determining all the zeros of a polynomial simultaneously has been considered by many, nonetheless a lot more is still being sought.

Without loss of generality, let us consider monic polynomials i.e. polynomials with 1 as leading coefficient.

Let $\mathrm{P}(\mathrm{z})=\prod_{\mathrm{i}=1 \text { to } n}\left(\mathrm{z}-\mathrm{w}_{\mathrm{i}}\right)$

be such a polynomial with $\mathrm{w}_{\mathrm{i}}, \mathrm{i}=1,2, \ldots, \mathrm{n}$ - assumed distinct as its zeros and $\mathrm{z}_{\mathrm{i}}$

$\mathrm{i}=1,2, . ., \mathrm{n}-$ also assumed distinct - as their approximations. Rewriting (1) as:

$\mathrm{P}(\mathrm{z})=\prod_{\mathrm{i}=1 \text { to n }}\left(\mathrm{z}-\mathrm{W}_{\mathrm{i}}\right)=\prod_{\mathrm{i}=1 \text { ton }}\left(\mathrm{z}-\mathrm{Z}_{\mathrm{i}}-\Delta_{\mathrm{i}}\right)$

Or in expanded form, we have:-

$\mathrm{P}(\mathrm{z})=\prod_{\mathrm{i}=1 \text { to n }}\left(\mathrm{z}-\mathrm{Z}_{\mathrm{i}}\right)-\sum_{\mathrm{i}=1 \text { to n }} \Delta_{\mathrm{i}} \prod_{\mathrm{k}=1}$ to $\mathrm{n}, \mathrm{k} \neq \mathrm{i}\left(\mathrm{z}-\mathrm{Z}_{\mathrm{k}}\right)+$ $\sum_{\mathrm{i}=1 \text { to n }} \Delta_{\mathrm{i}} \sum_{\mathrm{j}=\mathrm{i}+1 \text { to }} \Delta_{\mathrm{j}} \prod_{\mathrm{k}=1}$ to $\mathrm{n}, \mathrm{k} \neq \mathrm{i}, \mathrm{j}\left(\mathrm{Z}-\mathrm{Z}_{\mathrm{k}}\right)+\ldots$ ......(Higher Order Terms

Putting $\mathrm{z}=\mathrm{z}_{\mathrm{r}}$ in Eq. (3), we have

$\mathrm{P}\left(\mathrm{z}_{\mathrm{r}}\right) \quad=-\sum_{\mathrm{i}=1 \text { to n }} \Delta_{\mathrm{i}} \prod_{\mathrm{k}=1}$ to n, $\mathrm{k} \neq \mathrm{i}\left(\mathrm{z}_{\mathrm{r}}-\mathrm{z}_{\mathrm{k}}\right)+$

$\sum_{\mathrm{i}=1 \text { to n }} \Delta_{\mathrm{i}} \sum_{\mathrm{j}=\mathrm{i}+1 \text { to n }} \Delta_{\mathrm{j}} \prod_{\mathrm{k}=1}$ to $\mathrm{n}, \mathrm{k} \neq \mathrm{i}, \mathrm{j}\left(\mathrm{Z}_{\mathrm{r}}-\mathrm{Z}_{\mathrm{k}}\right)+$

Defining $\mathrm{Q}(\mathrm{z})=\prod_{\mathrm{i}=1 \text { to } \mathrm{n}}\left(\mathrm{z}-\mathrm{Z}_{\mathrm{i}}\right)$

and noting that $\mathrm{Q}\left(\mathrm{z}_{\mathrm{r}}\right)=0 \neq \mathrm{Q}^{\prime}\left(\mathrm{z}_{\mathrm{r}}\right)=\prod_{\mathrm{i}=1 \text { to } \mathrm{n}, \neq \mathrm{r}}\left(\mathrm{z}_{\mathrm{r}}-\mathrm{z}_{\mathrm{i}}\right), \mathrm{r}=1,2, \ldots, \mathrm{n}$ (6)
It can be established that

$\sum_{\mathrm{i}=1 \text { to n }} \Delta_{\mathrm{i}} \prod_{\mathrm{k}=1}$ to n, $\mathrm{k} \neq \mathrm{i}\left(\mathrm{Z}_{\mathrm{r}}-\mathrm{Z}_{\mathrm{k}}\right)=\Delta_{\mathrm{r}} \cdot \mathrm{Q}^{\prime}\left(\mathrm{Z}_{\mathrm{r}}\right)$

\section{DERIVATION OF THE METHOD}

On ignoring Higher Order Terms and from Eq.s (4) to (7), we can deduce :-

$\mathrm{P}\left(\mathrm{z}_{\mathrm{r}}\right)+\Delta_{\mathrm{r}} \mathrm{Q}^{\prime}\left(\mathrm{z}_{\mathrm{r}}\right)-\Delta_{\mathrm{r}} \cdot \mathrm{Q}^{\prime}\left(\mathrm{z}_{\mathrm{r}}\right) \cdot \sum_{\mathrm{i}=1 \text { ton, } \mathrm{i} \neq \mathrm{r}} \Delta_{\mathrm{i}} /\left(\mathrm{Z}_{\mathrm{r}}-\mathrm{Z}_{\mathrm{i}}\right)$

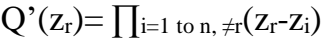

Now, truncating Eq.(8) after the $1^{\text {st }}$ order term we have

$\mathrm{P}\left(\mathrm{z}_{\mathrm{r}}\right)+\Delta_{\mathrm{r}} \cdot \mathrm{Q}^{\prime}\left(\mathrm{Z}_{\mathrm{r}}\right) \quad=0$

Giving $\Delta_{\mathrm{r}}=\mathrm{P}\left(\mathrm{z}_{\mathrm{r}}\right) / \mathrm{Q}^{\prime}\left(\mathrm{z}_{\mathrm{r}}\right)$

hence-forth denoted by $\partial_{\mathrm{r}}\left(\approx-\mathrm{P}\left(\mathrm{z}_{\mathrm{r}}\right) / \mathrm{Q}^{\prime}\left(\mathrm{z}_{\mathrm{r}}\right)\right)$, the expression given by Durand Kerner, known to give quadratic convergence.

Truncating Eq. (4) after the $2^{\text {nd }}$ order term, we obtain Eq (8), which can be rearranged to give an expression for $\Delta_{\mathrm{r}}$ - the theme of our method, namely:-

$\Delta_{r}=-\mathbf{P}\left(\mathbf{z}_{r}\right) / Q^{\prime}\left(\mathbf{z}_{r}\right)\left[1-\sum_{i=1 \text { to }}, \mathbf{i} \neq \mathbf{r} \Delta_{i} /\left(\mathbf{z}_{r}-\mathbf{z}_{\mathbf{i}}\right)\right]^{-1}$

For practical computational purposes and with $\partial_{\mathbf{r}}\left(\approx-\mathbf{P}\left(\mathbf{z}_{\mathbf{r}}\right) /\right.$ $\mathbf{Q}^{\prime}\left(\mathbf{z}_{\mathbf{r}}\right)$ ), this may be approximated and rephrased as :-

$\Delta_{\mathrm{r}} \approx \partial_{\mathrm{r}} /\left[1-\sum_{\mathrm{i}=1 \text { to }}, \mathrm{i} \neq \mathrm{r} \partial_{\mathrm{i}} /\left(\mathrm{z}_{\mathrm{r}}-\mathrm{z}_{\mathrm{i}}\right)\right]$

\section{CONCLUSION AND COMMENTS}

The method is simple and easy to apply.

To understand and really comprehend the computational procedure and to have a feeling of the effectiveness of the method, appreciating its convergence rate, without loss of generality, it suffices to give an example of a cubic and confine our attention to finding the improvements to the initial crude approximations obtained via the first iteration cycle. 


\section{International Journal of Engineering Applied Sciences and Technology, 2021 \\ Vol. 5, Issue 12, ISSN No. 2455-2143, Pages 305-306 \\ Published Online April 2021 in IJEAST (http://www.ijeast.com)}

Further better improvements can be attained via executing the pattern - repeatedly - with the new updated z's after the $\Delta$ 's have been incorporated in them.

\section{IV. .EXAMPLE}

Consider the polynomial $\mathrm{P}(\mathrm{z})=\mathrm{z}^{3}-\mathrm{z}^{2}-81 \mathrm{z}+81$, with $10,-10$ and 0 as crude approximations to its zeros $: 9,-9$ and 1 .

\begin{tabular}{|c|c|c|c|}
\hline $\mathrm{Z}$ & $\mathrm{Z}_{1}=10$ & $\mathrm{Z}_{2}=-10$ & $\mathrm{Z}_{3}=0$ \\
\hline $\mathrm{P}\left(\mathrm{z}_{\mathrm{r}}\right)$ & 171 & -209 & 81 \\
\hline $\mathrm{Q}^{\prime}\left(\mathrm{z}_{\mathrm{r}}\right)$ & 200 & 200 & -100 \\
\hline$\partial_{\mathrm{r}}$ & -.855 & 1.045 & .81 \\
\hline$\Delta_{\mathrm{r}}$ & -.986 & .9705 & .999 \\
\hline
\end{tabular}

Updating $\mathrm{Z}_{\mathrm{r}}$ by $\Delta_{\mathrm{r}}$ above $\mathrm{r}=1,2,3-$ in the light of the method we have

\begin{tabular}{|c|c|c|}
\hline$=9.014(9)$ & $z_{2}=-9.0295(-9)$ & $\mathrm{Z}_{3}=\underset{* *}{.9994(1)}$ \\
\hline
\end{tabular}

** numbers in () represent the actual zeros, quoted for comparison.

\section{REFRENCES}

[1] Aberth Oliver, " iteration methods for finding all zeros of a polynomial simultaneously",Maths. Comp.,vol. 27, \# 122, April 1973, pp. 339 - 344.

[2] B. Neta, M.Scott,C.Chun "Baisins of attraction for several methods to find simple roots of non-linear equations ", Applied,\# Mathematics and Computation vol.218, \# 21, 2012.

[3] Durand E., "Solutions numeriques des equations algebriques",Tome I: Equations du type $\mathrm{F}(\mathrm{x})=0$, Racines d'un polynome, Masson,Paris1960.

[4] Ehrlich I.W., " A modified Newton method for polynomials", Comm. Of the ACM.,VOL, 10 , \# 2,Feb. 1967, pp. $107-108$.

[5] Gargantini Irene and Henrici Peter "Cicular arthimetic and the determination of polynomial zeros “, Numer. M Maath., vol.18,1972, pp. 305 - 320.

[6] Henrici P, and Watkins B.O., " Finding zeros of a polynomial by the Q-D algorithm", Comm. Of the A.C.M., vol. 8, \#9 ,Eept. 1965, 570 - 574.

[7] Kerner I.O. “ Ein Gesamtschrittverfahren zur Beresch-nung der Nullstellen von Polynomen”,Numer. Math.,vol. 8, 1966 pp. 290 -294.
[8] Petko D proinov and Maria T Vasilova , “ On the convergence of higher-order Ehrlich -type iterative methods for approximating all zeros of a polynomial simultaneously", Journal of Inequalities and Applications, article \# 336, (2015). 